\title{
Comparison of inguinal hernia repair under local anesthesia versus spinal anesthesia.
}

\author{
Pradeep Goyal, Shiv Kumar Sharma , Kamaljeet Singh Jaswal, Sandeep Goyal , \\ Mushtaq Ahmed, Gauravrai Sharma, Poonam Pandotra.
}

\begin{abstract}
:
Background. Inguinal hernia is one of the most common diseases in the males. Treatment of this pathology is exclusively surgical. While in the past hernia surgery was carried out mainly under general and spinal anesthesia, in recent years there has been growing emphasis on the role of local anesthesia. Local anesthesia for inguinal hernia repair is cost-effective, but fear of intra-operative pain may hinder its widespread use.

Objectives.To evaluate the safety and effectiveness of inguinal hernia repair under local anaesthesia. To compare the inguinal hernia repair under local anaesthesia versus spinal anaesthesia in relation with post operative pain, complications and hospital stay.

Material and Methods; This prospective study comprised of 50 cases of inguinal hernia which were randomly divided into two groups of 25 each named group A and group B. Inguinal hernia mesh repair was done under local anaesthesia in group A and under spinal anaesthesia in group B. All the parameters were recorded intra and postoperatively in both groups. Data was compiled and subjected to statistical analysis by using "paired student $t$ test".

conclusion: Tension-free mesh repair under local anaesthesia is simple, safe, cost effective, very low rates of complications and a speedy discharge.

Keywords: Local Anaesthesia, Inguinal hernia repair, Lichtenstein mesh hernioplasty.
\end{abstract}

\section{Introduction}

Hernias are among the oldest known afflictions of human kind and elective inguinal hernia repair is commonly performed operation in general surgery. ${ }^{1}$ Inguinal hernia repair can be performed by using a variety of anaesthetic techniques such as, general anaesthesia, regional anaesthesia in the form of spinal or epidural anaesthesia, paravertebral block and local anaesthesia. ${ }^{2}$ The choice of anaesthesia and advantages of any one technique over another have been a subject of debate. Patient safety and the provision of optimum operating conditions for the surgeon are two main criteria for choice of anaesthetic technique for inguinal hernia repair. General and regional anaesthesia both have been reported to cause haemodynamic changes during induction and maintenance.

Local anaesthesia has been found to be the best anaesthesia for inguinal hernia repair. The use of local anaesthesia in hernia repair varies from a few percent in Sweden, $18 \%$ in Denmark and upto almost $100 \%$ in specialised institutions like Shouldice clinic, Toronto clinic and others totally dedicated to hernia surgery. ${ }^{4}$ However, general or spinal anaesthesia are still the most common types of anaesthesia being used in India and other developing countries. Studies comparing the recovery profiles of local, general and regional anaestheisia show that local anesthesia is ideal for day care surgery. ${ }^{5}$ Local anaesthesia provides increased safety for patients, better postoperative pain control, shorter recovery period with reduced duration of hospital stay and reduced cost, hence local anaesthesia is acceptable and safe technique for inguinal hernia surgery. ${ }^{6-12}$

The aim of this prospective study was to compare the safety, effectiveness, post operative complications and hospital stay in hernia surgery done under local anaesthesia versus spinal anaesthesia.

\section{Material and Methods}

This prospective study was conducted in Indira Gandhi Medical College and Hospital, Shimla for a period of one year w.e.f $1^{\text {st }}$ January 2010 to $31^{\text {st }}$ December 2010 .This study had included 50 cases of inguinal hernia. After admission to the hospital detailed history was taken and thorough clinical examination was done. Routine investigations like hemoglobin, total leucocyte count, differential leucocyte count, erythrocyte sedimentation rate, random blood sugar, renal function tests, chest X-ray and electrocardiogram were done in every case. Body Mass Index (BMI) of each patient was noted. It was calculated by formula Wt. $(\mathrm{kg}) / \mathrm{ht} .^{2}(\mathrm{~m})$. Normal range was taken between 18.50-24.99. ${ }^{98}$ Written consent was taken in every case. Patients were divided randomly into two groups of 25 each named Group A and Group B. Patients in group A were subjected to inguinal hernia mesh repair under local anaesthesia and patients in group B were subjected to inguinal hernia 
mesh repair under spinal anaesthesia. In group A patients, anaesthetic solution was consist of 50:50 mixture of $1 \%$ xylocaine and $0.5 \%$ bupivacaine with 1:2, 00,000 epinephrine. A skin weal was raised $2.5 \mathrm{~cm}$ from the iliac crest along the line joining anterior superior iliac spine to umbilicus. A needle was then passed through this to strike the inner surface of ilium just below the crest. $10 \mathrm{ml}$ of the solution was deposited as needle was slowly withdrawn. The injection was repeated with the needle reinserted at a slightly steeper angle and $5 \mathrm{ml}$ of solution was deposited. Second point of block was $2 \mathrm{~cm}$ above the mid inguinal point. The needle was inserted perpendicularly until it pierced the aponeurosis of external oblique. $10 \mathrm{ml}$ of solution was deposited at this depth and $5 \mathrm{ml}$ as needle was withdrawn over $2 \mathrm{~cm}$. Next a weal was raised over the pubic tubercle and subperiosteal injection of $3 \mathrm{cc}$ of solution was made. The block was completed by a subcutaneous infiltration along the line of surgical incision and $10 \mathrm{ml}$ of solution was deposited. In group B patients, regional anaesthesia in the form of spinal was given by using $0.5 \%$ bupivacaine. Under all aseptic conditions subarachnoid puncture was performed using a mid line lumbar approach with patient in sitting or lateral position. Using 26 gauge spinal needle in $\mathrm{L}_{3}-\mathrm{L}_{4}$ interspace. $12.5 \mathrm{mg}(2.5 \mathrm{cc})$ of $0.5 \%$ bupivacaine was injected in subarachnoid space after getting free flow of cerebrospinal fluid (CSF). Patient was turned supine. ${ }^{99}$ In case of inadequate or no effect local or spinal anaesthesia was converted into general anaesthesia and patient was not included in the study.

The following cases were excluded from the study:-

1. Complicated hernia like irreducible hernia, obstructed hernia, strangulated hernia and all patients who underwent emergency operations.

2. Patients who underwent bilateral herniorrhaphy, appendicectomy.

3. Recurrent hernia.

Tension free Lichtenstein hernioplasty was done in both groups Material used for hernioplasty was Polypropylene Prosthetic mesh with dimensions of $15 \times 7.5 \mathrm{~cm}$. After the surgery following observations were made:- Any pain or discomfort to the patient during surgery under local anaesthesia. Post operative ,Pain at the incision site ,Urinary retention,Wound haematoma ,Sepsis ,Headache,Testicular pain/Swelling. Follow up of the patients were carried out on $3^{\text {rd }}$ and $7^{\text {th }}$ postoperative days as out patient. In follow up patients were assessed for any wound sepsis, persistent pain at incisional site and any other complication. All the data collected was statistically analysed by using the "Paired Student $t$ test". The post operative pain, complications and hospital stay were compared in the two groups A \& B.

\section{Results}

The youngest patient was of 24 years in group A and 18 years in group B. The oldest patient was of 77 years in group A and 76 years in group B. The mean age was $46.2 \pm 16.64$ years in group A and $42.56 \pm 16.71$ years in group B. All patients operated in this study were males. The incidence of indirect inguinal hernia was higher as compared to direct hernia in both the groups. In group A, 16 (64\%) patients had indirect inguinal hernia and $9(36 \%)$ patients had direct inguinal hernia. In group B, $20(80 \%)$ patients had indirect inguinal hernia and $5(20 \%)$ patients had direct inguinal hernia. Indirect hernia incidence was common in age group of 26 -46 years in group A and $18-52$ years in group B. Direct hernia incidence was common in age group of $50-77$ years in group A and $59-76$ years in group B. In group A, 17(68\%) patients had inguinal hernia on right side and $8(32 \%)$ patients had hernia on left side. In group B, 15(60\%) patients had inguinal hernia on right side and $10(40 \%)$ patients had hernia on left side. The time taken to complete operation under both types of anaesthesia was noted down. The time was calculated in both the groups from the time of anaesthesia till dressing ( $p$ $<0.05)$ (Table 1.)

Table 1 Time taken for surgery

\begin{tabular}{|c|c|c|c|c|}
\hline \multirow{2}{*}{$\begin{array}{c}\text { Time } \\
\text { taken } \\
\text { (in } \\
\text { minutes) }\end{array}$} & \multicolumn{2}{|c|}{$\begin{array}{l}\text { Group A (Local } \\
\text { Anaesthesia) }\end{array}$} & \multicolumn{2}{|c|}{$\begin{array}{l}\text { Group B (Spinal } \\
\text { Anaesthesia) }\end{array}$} \\
\hline & $\begin{array}{l}\text { No. } \\
\text { of } \\
\text { cases }\end{array}$ & $\begin{array}{l}\text { Percent } \\
\text { age }\end{array}$ & $\begin{array}{l}\text { No. of } \\
\text { cases }\end{array}$ & $\begin{array}{l}\text { Percen } \\
\text { tage }\end{array}$ \\
\hline $20-30$ & 4 & $16 \%$ & 0 & - \\
\hline $31-40$ & 9 & $36 \%$ & 2 & $8 \%$ \\
\hline $41-50$ & 9 & $36 \%$ & 3 & $12 \%$ \\
\hline $51-60$ & 3 & $12 \%$ & 10 & $40 \%$ \\
\hline $61-70$ & 0 & - & 3 & $12 \%$ \\
\hline $71-80$ & 0 & - & 4 & $16 \%$ \\
\hline $81-90$ & 0 & - & 3 & $12 \%$ \\
\hline
\end{tabular}

$\mathrm{P}<0.5$

During surgery patients were observed for the degree of pain and any pain felt during surgery was noted down. (Table 2 )The difference was statistically significant $(\mathrm{p}<0.05)$. 
Comparison of inguinal hernia repair under local anesthesia versus spinal anesthesia.

Table 2 Pain felt during surgery

Group A patients felt statistically significantly less pain as compared to group B patients. $(\mathrm{p}<0.05)$

\begin{tabular}{|c|c|c|c|c|}
\hline \multirow{2}{*}{$\begin{array}{l}\text { Pain Felt } \\
\text { during } \\
\text { surgery }\end{array}$} & \multicolumn{2}{|c|}{$\begin{array}{l}\text { Group A } \\
\text { Anaesthesia) }\end{array}$} & \multicolumn{2}{|c|}{$\begin{array}{l}\text { Group B } \\
\text { Anaesthesia) }\end{array}$} \\
\hline & $\begin{array}{l}\text { No. of } \\
\text { cases }\end{array}$ & Percentage & No. of cases & Percentage \\
\hline No pain & 2 & $8 \%$ & 0 & - \\
\hline Mild & 17 & $68 \%$ & 11 & $44 \%$ \\
\hline Moderate & 5 & $20 \%$ & 14 & $56 \%$ \\
\hline Severe & 1 & $4 \%$ & 0 & - \\
\hline
\end{tabular}

The post operative pain was recorded at 12 hours, 24 hours and 48 hours after operation by using visual analogue scale (VAS) pain scoring system.(Table 3 ).

Table 3 Trends in post-operative pain scores (visual analog scale)

\begin{tabular}{|l|l|l|l|l|l|l|}
\hline \multirow{2}{*}{$\begin{array}{c}\text { Time interval } \\
\text { (in hours) }\end{array}$} & $\begin{array}{l}\text { Group A } \\
\text { (Local Anaesthesia) }\end{array}$ & \multicolumn{2}{l|}{$\begin{array}{l}\text { Group B } \\
\text { (Spinal Anaesthesia) }\end{array}$} & t-value & p-value \\
\cline { 2 - 7 } & Mean & S.D. & Mean & S.D & & \\
\hline 12 & 3.32 & 1.14 & 4.32 & 1.18 & 3.04 & $0.004^{*}$ \\
\hline 24 & 2.00 & 1.00 & 2.72 & 1.13 & 2.37 & $0.022^{*}$ \\
\hline 48 & 0.76 & 0.72 & 1.04 & 0.84 & 1.26 & 0.213 \\
\hline
\end{tabular}

The mean pain was statistically significantly less in group A as compared to group B. $(\mathrm{p}<0.05)$

Table 4 Incidence of post operative complications

\begin{tabular}{|l|l|l|l|l|}
\hline \multirow{2}{*}{$\begin{array}{l}\text { Post operative } \\
\text { Complications }\end{array}$} & \multicolumn{2}{|l|}{ Group A (Local Anaesthesia) } & \multicolumn{2}{l|}{ Group B (Spinal Anaesthesia) } \\
\cline { 2 - 5 } & No. of cases & Percentage & No. of cases & Percentage \\
\hline Wound Haematoma & 0 & - & 0 & - \\
\hline Wound Sepsis & 1 & $4 \%$ & 3 & $12 \%$ \\
\hline Testicular pain/swelling & 1 & $4 \%$ & 0 & - \\
\hline Urinary retention & 0 & - & 5 & $20 \%$ \\
\hline Headache & 0 & - & 0 & - \\
\hline Respiratory complications & 0 & - & 0 & - \\
\hline Thromboembolism & 0 & - & 0 & - \\
\hline Recurrence & 0 & - & 0 & - \\
\hline
\end{tabular}

Postoperative complications, wound sepsis and urinary retention were significantly less in group A as compared to group B.

Table 5 Number of analgesic doses received postoperatively

\begin{tabular}{|l|l|l|l|l|}
\hline \multirow{2}{*}{ No. of analgesic doses } & \multicolumn{2}{|l|}{ Group A (Local Anaesthesia) } & \multicolumn{2}{l|}{ Group B (Spinal Anaesthesia) } \\
\cline { 2 - 5 } & No. of cases & Percentage & No. of cases & Percentage \\
\hline 0 & 0 & - & 0 & - \\
\hline 1 & 12 & $48 \%$ & 1 & $4 \%$ \\
\hline 2 & 4 & $16 \%$ & 5 & $20 \%$ \\
\hline 3 & 8 & $32 \%$ & 11 & $44 \%$ \\
\hline 4 & 0 & - & 0 & - \\
\hline 5 & 0 & - & 4 & $16 \%$ \\
\hline 6 & 1 & $4 \%$ & 4 & $16 \%$ \\
\hline Mean \pm S.D. & $2 \pm 1.22$ & & $3.48 \pm 1.53$ & \\
\hline
\end{tabular}

t-value -3.775

p-value $-<0.05$

Mean analgesic dose received was statistically significantly less in group A patients $(2 \pm 1.22)$ as compared to group B patients $(3.48 \pm 1.53) .(\mathrm{p}<0.05)$

$15(60 \%)$ patients of group A and $9(36 \%)$ patients of group B, were kept indoor for one day. $6(24 \%)$ patients of group A and $8(32 \%)$ patients of group B were kept for two days. 3(12\%) patients of group B were in the hospital for three days. 3(12\%) patients of group A and $2(8 \%)$ patients of group B were kept indoor for four days. 1(4\%) patient of group A and 2(8\%) patients of group B were in the hospital for five days. 1(4\%) patient 
Comparison of inguinal hernia repair under local anesthesia versus spinal anesthesia.

of group B was in the hospital for six days. Mean postoperative hospital stay was $1.76 \pm 1.2$ days in group A and $2.32 \pm 1.46$ days in group B. It was statistically significantly less in group A as compared to group B. (p <0.05). $2(8 \%)$ patients of group A and $2(8 \%)$ patients of group B resumed normal work by the end of 2 day. 5(20\%) patients of group A and 1(4\%) patient of group B resumed normal work after 3 days. 4(16\%) patients of group B took four days to resume normal work. 7(28\%) patients of group A and 3(12\%) patients of group B resumed normal work by the end of fifth day. 1(4\%) patient of group A took six days to resumed normal work. 8(32\%) patients of group A and $8(32 \%)$ patients of group B resumed normal work by the end of 7 day. 2(8\%) patients of group A and 7(28\%) patients of group B took more than seven days to resume normal work. Mean time taken to resume work in group A was 5.6 \pm 2.64 days and $7.04 \pm 3.51$ days in group B. It was statistically significant $(\mathrm{P}<0.05)$.

\section{Discussion}

In present study the age of the patients in group A was in the range of 22-77 years and in group B was 18-76 years. The mean age was $46.2 \pm 16.64$ years in group A and $42.56 \pm 16.71$ years in group B. All the patients were male.The study conducted by Kark AE et al (1998) ${ }^{13}$ showed that out of total 3175 patients, $97 \%$ of the patients operated were males and ranged between 15-92 years of age. The study conducted by Song et al $(2000)^{14}$ included 50 patients with mean age of patients $42 \pm 18$ years in the group operated under local

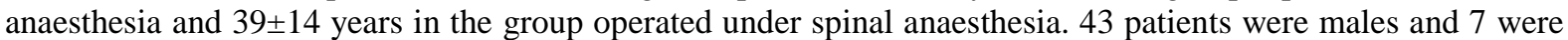
females. Several other studies like by Ryan et al (1984) ${ }^{15}$, Young DV ${ }^{2}$ (1987), O' Dwyer et al $(2002)^{12}$ and Erdem E (2003) ${ }^{16}$ also showed similar results. Age and sex incidence of patients in our study were similar to that in other studies.

In present study $16(64 \%)$ patients had indirect inguinal hernia in group A and $20(80 \%)$ patients in group B. Direct type of inguinal hernia was present in $9(36 \%)$ patients of group A and $5(20 \%)$ patients of group B. The results of our study were almost similar to the other studies ${ }^{13,15,17,18,19}$.

In present study $17(68 \%)$ patients in group A and 15(60\%) patients in group B had right sided inguinal hernia. Left sided hernia was present in $8(32 \%)$ patients in group A and $10(40 \%)$ in group B. The results of present study were comparable to the studies ${ }^{12,120}$. conducted by others. Right side of inguinal hernia is more common due to the later descent of right testis and high incidence of patent processus vaginalis on the right side. $^{13}$

In present study the mean operative time was $42.8 \pm 8.6$ minutes in group A and $64.45 \pm 13.7$ minutes in group B. The results of our study were similar to the other studies conducted by Song et al (2000) ${ }^{14}$,Job C et al $(1979)^{21}$ and Young DV (1987) ${ }^{2}$.

Pain is the most common concerned factor to the patient undergoing surgery. Although pain is typically regarded as primary indicator of tissue damage, it does not always correlate with an identifiable causative injury. The perception of pain is supported by sensory neurons (nociceptors) and neural afferent pathways. ${ }^{22,23}$ In the present study in group A, 17(68\%) patients felt mild pain and five (20\%) patients felt moderate pain. However in group B, 11(44\%) patients felt mild pain and $14(56 \%)$ patients felt moderate pain. The difference is statistically significant. The results of our study were comparable to other studies. The study conducted by Earle AS (1960) ${ }^{124}$ on 46 patients showed $23(50 \%)$ patients experienced slight pain and remaining 23 (50\%) felt no pain during inguinal hernia repair under local anaesthesia. Study done by Baskerville PA et al (1983) ${ }^{25}$ on 129 patients operated under local anaesthesia demonstrated that $93 \%$ patients felt no pain during operation and $7 \%$ said operation was painful. Pain during operation is felt in case of large hernia operated under local anaesthesia, if dissection is difficult due to adhesions of the sac, and this may lead to conversion of local anaesthesia to general anaesthesia. ${ }^{8,26}$ If local anaesthesia is given by experienced surgeon, it is well accepted by the patients. ${ }^{13}$ Studies done by Wellword et al $(1998)^{27}$, Amid PK et al $(1998)^{28}$, Song D et al $(2000)^{14}$, Callesen T et al $(2001)^{6}$ demonstrated that conversion of local anaesthesia to general anaesthesia was because of pain during dissection or reposition of the hernia sac.

Post operative pain is due to traction on certain tissues particularly peritoneum, inadequate analgesia, urinary retention and wound infection. ${ }^{2}$ It follows the known distribution of the regional nerves including ilio inguinal, ilio hypogastric and genital branch of genitofemoral nerve. It can be prevented by meticulously avoiding excess manipulation of the nerves. ${ }^{29}$ Post operative pain was scored with visual analog scale. Pain immediately after operation was assessed by dosage of analgesic consumption.

In the present study, post operative pain was recorded at 12 hours, 24 hours and 48 hours after operation by using visual analog scale. The mean visual analog scores at 12 hours interval, 24 hours interval and 48 hours interval were $3.32 \pm 1.14,2.00 \pm 1.00$ and $0.76 \pm 0.72$ in group $A$ and $4.32 \pm 1.18,2.72 \pm 1.13$ and $1.04 \pm 0.84$ in group B respectively. The mean pain visual analog score is statistically significantly less in group A as compared to group B. (Table 3) The results of our study were comparable to others studies conducted by Song $\mathrm{D}$ et al (2000) ${ }^{14}$ showed that VAS scores were $15 \pm 1.4$ in patients operated under local anaesthesia compared to 
$34 \pm 3.2$ in patients operated under spinal anaesthesia. Post operative pain was statistically less in patients operated under local anaesthesia.

In the present study 24(96\%) patients in group A received $1-3$ analgesic doses postoperatively compared to $16(64 \%)$ patients in group B. 5 or more doses were received only by 1(4\%) patient in group A and $8(32 \%)$ patients in group B. The mean dose received in group A was $2 \pm 1.22$ and $3.48 \pm 1.53$ in group B. The difference in mean doses of analgesics received by group A and group B is statistically significant. The study conducted by Young DV $(1987)^{2}$ showed that no postoperative analgesics were required in $22 \%$ patients operated under local anaesthesia compared to $8 \%$ in patients operated under spinal anaesthesia. The study done by Kark et al (1998) ${ }^{13}$ on 3175 patients demonstrated $60 \%$ needed oral analgesics (2-3 doses) for a mean of 6 days. The results of our study were similar to the results shown by others. Less analgesic doses required in patients operated under local anaesthesia is due to the long postoperative analgesic effect of local anaesthesia. ${ }^{6}$ In the present study $15(60 \%)$ patients were kept indoor for 1 day in group A and $9(36 \%)$ patients in group B. $15(60 \%)$ patients in group A resumed work after 7 days whereas most of group B patients took more than 7 days to resume normal activities or work. The study done by Teasdale et al (1982) ${ }^{30}$ on 103 patients found faster recovery after local anaesthesia as compared to general and spinal anaesthesia. The study conducted by Barkerville PA et al $(1983)^{25}$ showed that return to normal activity by $3^{\text {rd }}$ post operative day in 49 (38\%) patients, by end of 1 week in $78 \%$ patients and by end of 2 weeks in $98 \%$ patients. The study conducted by Song D et al $(2000)^{14}$ found that the time to discharge to be shorter after local anaesthesia (158 minutes) than after general (208 minutes) and spinal anaesthesia (308 minutes The decrease in time for return to work was explained by encouragement of patients to resume work as early as possible. The residual effects of general and spinal anaesthesia like nausea, vomiting, sedation and urinary retention results in increased hospital stay. ${ }^{2,6,9}$ The lower incidence of major complications attributes to early mobility following local anaesthesia. ${ }^{31}$

The inguinal hernia repair is a common surgery with almost no mortality. The emphasis is on low rates of recurrence and other complications like wound haematoma, wound sepsis, testicular pain/ swelling, urinary retention, headache and respiratory complications. The choice of anaesthesia and surgical technique depend on low complication rates. In present study wound sepsis was present in $1(4 \%)$ patient of group A and $3(12 \%)$ patients of group B. No patients in either group had wound haematoma. There was no case of mesh infection. The study conducted by Shulman AG et al $(1994)^{8}$ reported no cases of mesh infection in 3019 open tensionfree mesh hernioplasty. The study done by Kark AE et al (1995) ${ }^{9}$ reported no case of mortality, over all sepsis rate was $0.9 \%$. The study conducted by Gianetta E et al $(1997)^{7}$ showed that inguinal hernia repair in elderly under local anaesthesia had 3(1\%) wound infections. They showed that general anaesthesia and spinal anaesthesia were associated with higher rates of serious postoperative complications and occasional post operative death. The results of our study were comparable to the other studies. In the present study there was no urinary retention in group A patients whereas 5 (20\%) patients of group B had urinary retention after surgery. Accumulated data from other hernia literature suggest that incidence of urinary retention is lowest with local anaesthesia compared with both regional and spinal anaesthesia. ${ }^{9,12}{ }^{2}$. Results of present study were similar to the studies conducted by Teasdale et al $(1982)^{115}$ Young DV $(1987)^{2}$ Callesen et al $(2001)^{6}$ others. Although the exact cause of high frequency urinary retention in spinal anaesthesia group patients is not known, it is thought to be secondary to prolonged block of bladder autonomic innervation. It may be also related to age of the patient and volume of fluid received. Fluids restriction during operation can reduce the risk of urinary retention. ${ }^{14}$,

In the present study we found that Lichtenstein's hernioplasty under local anaesthesia is safe, simple, effective, economical, with no mortality, less post operative complications and long postoperative analgesia. Inguinal hernia repair under local anaesthesia provides better analgesia as compared to spinal anaesthesia reflected by fewer doses of analgesics required by patients operated under local anaesthesia.

\section{Conclusion}

The Lichtenstein tension-free hernioplasty under local anaesthesia has opened a new era in hernia surgery without the risk of serious morbidity. This procedure offers an extremely safe day care operation for the adults and very old with disabling disease. It is an inexpensive and effective procedure and the economic benefits are enhanced by the low morbidity, low recurrence rate, and early return to normal activities. It results in faster short-term recovery, speedier discharge, less anaesthesia related complications. In times to come it may be consider as the gold standard procedure for groin hernia repair.

\section{References}

[1]. Rutkow IM, Robbins AW, Demographic classificatory ,and socio economic aspects of hernia repair in the united states. Surg Clin N Am 1993; $73: 413$.

[2]. Young DV. Comparision of local, spinal and general anaesthesia for inguinal hernia repair. Am J Surg 1987;153:560-3.

[3]. Amado WJ. Anaesthesia for groin hernia surgery. Surg Clin N Am 1993; $73: 427-38$.

[4]. Callesen T. inguinal hernia repair: anaesthesia, pain and convalescene. Dan Med Bull 2003; 50(3): 203-18

[5]. Amado WJ. Anaesthesia for groin hernia surgery. Surg Clin N Am 2003; 83:1065 -77. 
[6]. Callesen T, Bech K, Kehlet H. One thousand consecutive groin hernia repairs under unmonitored local anaesthesia. Anesth analg 2001;93:1373-6.

[7]. Gianetta E, Decian F, Cuneo S, Friedman D, Vitale B, Marinari G et al. Hernia repair in elderly patients. Br J Surg 1997;84:983-5.

[8]. Amid PK, Shulman AG, Lichenstein IL. Local anaesthesia for inguinal hernia repair step by step procedure. Ann Surg 1994; 220: 735-7.

[9]. Kark AE, Kurzer M, Waters KJ. Tension-free mesh hernia repair; review of 1098 using local anaesthesia in a day unit. Ann R Coll Engl 1995; 77: 299-304.

[10]. Wantz GE. Ambulatory hernia surgery. Br J Surg 1989;76:1228-9.

[11]. Callesen T, Bech K, Kehlet H. The feasibility, safety, and cost of infiltration anaesthesia for hernia repair. Anaesthesia 1998:53:31-5

[12]. O’Dwyer PJ, Serpell MG, Millar K, Paterson C, Young DV, Hair A, et al. Local or general anaesthesia for open tension-free hernioplasty: A randomized trial. Ann Surg 2002; 237: 574-9.

[13]. Kark AE, Kurzer MN, Belsham PA. Three thousand one hundred seventy five primary inguinal hernia repairs ;advantages of ambulatory open mesh repair using local anaesthesia. Am J Coll Surg 1998;186:1541-7.

[14]. Song D, Greilich NB, White PF, Wateha MF, Tongier WK. Recovery profiles and costs of anaesthesia for outpatient unilateral inguinal herniorrhaphy. Anesth Analg 2000; 91: 876-81.

[15]. Ryan JA, Adye BA, Jolly PC, Murloy MF. Outpatient inguinal herniorrhaphy with both regional and local anaesthesia. Am J Surg 1984; 148: 313-6.

[16]. Erdem E. comparison of local and spinal anaesthesia techniques in inguinal hernia repair, Denizli turkey: Pamukkale University School of Medicine, 2003.

[17]. Lichenstein IL. Hernia repair without disability. $2^{\text {nd }}$ ed. St Louis, Tokyo. Ishiyaku Euroamercia, Inc; 1986.

[18]. Stobie B: Shouldice hospital dedicated to the repair of hernias. Can Oper Room Nurs J $1999 ; 17: 30-2$.

[19]. Glassow F. Inguinal hernia repair using local anaesthesia. Ann R Coll Surg Engl 1984; 66: 382

[20]. Gilbert AI. Classification for diagnosis of inguinal hernias. Am J Surg 1959;110:120-2

[21]. Job CA, Fernandez MA, Dorph DJ, Betcher AM. Inguinal hernia repair; Comparison of local, epidural, and general anesthesia.NY State J Med 1979;79(11):1730-3

[22]. Melzack R. Neurophysiological foundation of pain. In: sternbach RA, ed. The Psychology of pain. Newyork: Raven press: 1986; 1 12.

[23]. Melzack R, Casey KL. Sensory, motivational, and central control deter-minants of pain: A new conceptual model. In: Kenshalo D, ed. The skin senses. Springfield IL, Charles C. 1968; 423-9.

[24]. Earle AS. Local anaesthesia in inguinal hernia repair. Am J Surg 1960;100:782.

[25]. Baskerville PA, Jarrett PEM. Day care inguinal hernia repair under local anaesthesia. Ann R Coll Surg Engl 1983; 65: 224-5.

[26]. Jolon AM Meyer -bech D, Rosa AD, MarcosAG, Inguinal hernia repair under local anaesthesia,evalution of intraoperative discomfort. Br J Surg 1995; 82: 100-2.

[27]. Wellwood J, Sculpher MJ, Stocker D, Nicholls GJ, Geddes C, Singh R, et al. Randomised controlled trial of laparoscopic vs open mesh repair for inguinal hernia. Outcome and pain. Br Med J 1998; 317: 103-10.

[28]. Amid PK, Lichenstein IL. Long term results in current status of the Lichtenstein open tension-free hernioplasty. Hernia 1998; 2: 8994.

[29]. Tverkay M, Cozacov C, Ayache M, Bradley EL, Kassin I. Postoperative pain after inguinal herniorrhaphy with different types of anaesthesia. Anaesth Analg 1990; 70: 29-35.

[30]. Teasdale C, Mecrum A, William NB, Horton RE : A randomized controlled trial to compare local with general anaesthesia for short stay inguinal hernia repair. Ann R Coll Surg Engl 1982; $64: 238-242$.

[31]. Roder W, Weigel TF, Isemer FE. A concept for decreasing post operative pain after inguinal hernia operation. Langenbecks Arch Chir 1994; 379:80-3. 